\title{
Editorial
}

\section{Hacia la universidad que todos deseamos}

$\mathrm{L}$ a Institución Universitaria Escuela Colombiana de Rehabilitación, pujante desde sus inicios hace 54 años, se ha caracterizado a través del tiempo por el alto nivel de calidad en todos los aspectos, no sólo académicos, sino humanos y sociales.

Los derroteros que le señalaron los fundadores y preservan los directivos la han distinguido en el país y en el exterior como una institución sólida y confiable por sus productos, ni más ni menos que los profesionales del área de la rehabilitación que con eficiencia, ética, conocimientos y actitudes se dedican a la labor asistencial, ya en los hospitales, bien en las actividades docentes, como en la práctica privada.

Las tres carreras tradicionales de Fisioterapia, Terapia ocupacional y Fonoaudiología, ampliamente conocidas, han preparado y graduado varios centenares de profesionales, dedicados a la docencia, a la investigación y al servicio en el campo de la salud. Ellos viven orgullosos de la institución que los formó, al igual que ésta se ufana de cada uno de sus egresados por lo que representan como depositarios de sólidos conocimientos y poseedores de un profesionalismo sin tacha.

La mayor riqueza de la institución la constituyen su comunidad universitaria y sus egresados; muchos de éstos integran la planta docente ampliamente reconocida y respetada en el medio académico.

Actualmente la institución se enfrenta al gran reto de crecer y rebosar los límites de las disciplinas de formación que la han ocupado hasta ahora. Los importantes programas de especialización para rehabilitación de mano y miembro superior, para equilibrio metabólico y soporte nutricional, para cuidado respiratorio y audiología, entre otros, impulsan exitosamente el prestigio junto con los numerosos diplomados y actividades diferentes de educación continua que se llevan a cabo en el transcurso de cada año.

Pero no es suficiente lo alcanzado hasta ahora. En el cometido de proseguir en avanzada, con el fortalecimiento de la investigación y la reingeniería de toda la estructura funcional, la escuela se prepara para dar el paso a universidad, como la culminación de su objetivo de representar no solamente la institución modelo en Rehabilitación Integral de las personas en situación de discapacidad, sino de proyectarse a áreas del desarrollo físi- 
co, de las humanidades, de los soportes fundamentales para el cumplimiento de los propósitos del sistema de seguridad social en salud.

Con nuevas facultades de pregrado, atractivas especializaciones, desarrollo de programas para formación tecnológica se caminará con paso firme hacia los campos del saber que respondan fielmente a las metas trazadas.

Los diferentes estudios de factibilidad adelantados, los varios talleres realizados con docentes y expertos foráneos, las consultas diversas a pares académicos y a las propias autoridades de la educación nacional, comprueban que transitamos por el camino adecuado, pues dentro de los términos de elemental prudencia no es permisible generar gratuitas expectativas que afectarían la seriedad bien ganada de la entidad caracterizada siempre por su equilibrada sensatez.

Dentro del proceso preparatorio se han avizorado dificultades y obstáculos diversos que podrán allanarse con la férrea voluntad de todos los actores comprometidos en este avance necesario y justo.

La verdad es que vamos con la mira y la voluntad de alcanzar la universidad que todos deseamos...

Gustavo Malagón-Londoño,

Rector 